\title{
PERANCANGAN ALAT PERAGA HANTARAN KALOR SECARA RADIASI UNTUK MENENTUKAN PANJANG GELOMBANG
}

\author{
Mohamad Amin \\ Jurusan Teknik Mesin Politeknik Negeri Balikpapan \\ email : mohamad.amin@poltekba.ac.id
}

\begin{abstract}
Props heat conduction by radiation to determine the wavelength is strongly influenced by the type and color of the surface of the bulb. Surface color bulb will look like the color of the reflected light. Each color of the reflected light bulb has a different wavelength, the magnitude of the wavelength (nm) of each color of light is inversely proportional to the temperature (kelvin). Based on the experimental results wavelengths in the blue, green, and red color spectrum included in the interval corresponding to the wavelength of each color. Wavelength descending on the color of the bulb is of a red bulb at $740.254 \mathrm{~nm}, 499.638 \mathrm{~nm}$ for green, and blue at $469.278 \mathrm{~nm}$
\end{abstract}

Keywords: heat conduction, radiation, Wavelength, Wien shift law, the colors of the spectrum

\begin{abstract}
Abstrak
Alat peraga hantaran kalor secara radiasi untuk menentukan panjang gelombang sangat dipengaruhi oleh jenis dan warna permukaan dari bola lampu. Warna permukaan bola lampu akan terlihat seperti warna cahaya yang dipantulkan. Setiap warna cahaya yang dipantulkan bola lampu memiliki panjang gelombang yang berbeda, besarnya panjang gelombang $(\mathrm{nm})$ setiap warna cahaya berbanding terbalik dengan suhu (kelvin). Berdasarkan hasil percobaan panjang gelombang pada warna biru, hijau, dan merah termasuk didalam interval spektrum warna yang sesuai dengan panjang gelombang masing-masing warna. Panjang gelombang terbesar sampai terkecil pada warna bola lampu yaitu dari bola lampu berwarna merah sebesar 740,254 nm, hijau sebesar $499,638 \mathrm{~nm}$, dan biru sebesar 469,278 nm.
\end{abstract}

Kata kunci : Hantaran kalor, Radiasi,Panjang Gelombang, Hukum pergeseran Wein, warna spektrum

\section{Pendahuluan}

Semua bidang disiplin ilmu, seharusnya membawa para siswa pada kompetensi yang bisa mereka gunakan sehari-hari, bukan hanya pada tahapan mengetahui saja. Kenyataannya khusus untuk fisika sebagai salah satu komponen materi ajar disekolah menengah atas/ kejuruan ternyata mengalami kesulitan dalam penguasaannya oleh siswa. Dr. Tjia May On menyatakan "Pembelajaran Fisika di Indonesia membunuh kreativitas murid" "[1]. Dr. rer. nat. M.F Rosyid saat memberikan kritikan bagi pendidikan fisika yang menurutnya, "di Indonesia, ilmu fisika secara sistematis terpenjara di sekolahan dan bimbingan test" ${ }^{\text {"2] }}$. Siswa tidak diajak untuk ber-sains, melainkan hanya melantunkan fakta-fakta sains saja.
Sehingga hal ini tidak menjadi sesuatu yang bermakna bagi siswa, akhirnya minat kurang dan fisika dipandang sebagai sesuatu yang matematis dan tidak bermanfaat karena pendekatannya jarang kontekstual dan tidak memberikan kompetensi hidup bagi siswa. Kebanyakan menggunakan pendekatan matematis, sehingga bagi siswa fisika adalah angka dan rumus.

Oleh karena itu, perlu pendekatan lain yang bisa memberikan sudut pandang bahwa fisika itu bermakna. Sehingga perlu pendekatan yang lebih aplikatif bagi siswa, yang bisa mewariskan kemampuan bersains, tidak hanya melantunkan sains. Pemerolehan kemampuan ber-sainis ini sejalan dengan fungsi dan tujuan mata pelajaran fisika di tingkat SMA/K. 
Dari penjelasan di atas tampak bahwa penyelenggaraan mata pelajaran fisika di SMA/K dimaksudkan sebagai sarana untuk melatih para siswa agar dapat memiliki kompetensi ber-sains atau menguasai pengetahuan, konsep dan prinsip fisika, serta memiliki kecakapan ilmiah.

Penulis mencermati bahwa prestasi belajar baik itu kognitif, apektif, atau pun psikomotor bisa ditingkatkan dengan memberikan kompetensi ber-sains pada siswa. Kognitif, didapatkan dari proses siswa berinquary dan menemukan konsep menggunakan teori fisika. Psikomotor, didapatkan melalui mampunya siswa menggunakan berbagai instrument eksperimen untuk menemukan konsep fisika yang menjadi bahan ajar. Afektif, didapatkan dari bagaimana siswa bisa sabar dalam mendapatkan data, kemudian kemampuan untuk menunjukan data yang otentik, dan lainnya.

Selain itu Berdasarkan UU No. 15 tahun 2005, tentang guru dan dosen pada Bab. 4, pasal 10, ayat 1 "Kompetensi guru sebagaimana dimaksud dalam Pasal 8 meliputi kompetensi pedagogik, kompetensi kepribadian, kompetensi sosial, dan kompetensi profesional yang diperoleh melalui pendidikan profesi",[3]. Menyambung kompetensi pedagogik, tentunya guru berhak turut berprestasi, berkarya, mengembangkan kemampuan untuk menyusun perencanaan yang dirasa sangat diperlukan dalam pelaksanaan pembelajaran di lapangan. Berdasarkan uraian diatas dan dalam menghantarkan siswa memiliki kompetensi ber-sains dalam konteks fisika maka tujuan dari penelitian ini adalah untuk membuat rancangan alat peraga hantaran kalor secara radiasi di sekolah menengah atas.

\section{Kajian Teori}

\subsection{Hukum Pergeseran Wien}

Wilhelm Wien mempelajari hubungan antara panjang gelombang yang dipancarkan pada intensitas maksimum (panjang gelombang maksimum) dengan suhu mutlak sebuah benda yang dikenal hukum pergeseran Wien ${ }^{[4]}$. Hukum pergeseran Wien dapat dirumuskan sebagai berikut :

$\lambda$ maks $. \mathbf{T}=\mathbf{C}$

Dimana :

$\lambda$ maks $=$ Panjang gelombang maks. $(\mathrm{nm})$

$\mathbf{T}=$ Suhu Mutlak (Kelvin)

C $=2,898 \times 10-3 \mathrm{mK}=$ Konstanta Wien

\subsection{Spektrum Optik}

Spektrum optik atau cahaya/ spektrum tampak yaitu bagian dari spektrum elektromagnetik yang tampak oleh mata manusia secara langsung. Radiasi elektromagnetik dalam rentang panjang gelombang ini disebut sebagai cahaya tampak atau cahaya saja. Tidak ada batasan yang tepat dari spektrum. Mata normal manusia dapat menerima panjang gelombang dari 400 sampai 700 nanometer (nm), meskipun beberapa orang dapat menerima panjang gelombang dari 380 sampai $780 \mathrm{~nm}$. Mata yang telah beradaptasi dengan cahaya biasanya memiliki sensitivitas maksimum di sekitar $555 \mathrm{~nm}$, di wilayah hijau dari spektrum optik. Warna pencampuran seperti pink atau ungu, tidak terdapat dalam spektrum ini karena warna-warna tersebut hanya akan didapatkan dengan mencampurkan beberapa panjang gelombang. Panjang gelombang yang kasat mata diartikan oleh jangkauan spektral jendela optik, wilayah spektrum elektromagnetik yang melewati atmosfer. Radiasi elektromagnetik di luar jangkauan panjang gelombang optik, atau jendela transmisi lainnya hampir seluruhnya diserap oleh atmosfer. ${ }^{[5]}$

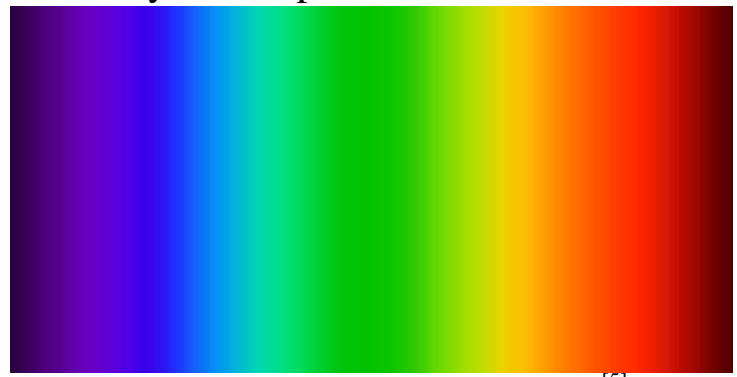

Gambar 1. Gambar Spektrum Optik ${ }^{[5]}$ 


\subsection{Warna-Warna dalam Spektrum}

Meskipun spektrum optik adalah spektrum yang kontinu sehingga tidak ada batas yang jelas antara satu warna dengan warna lainnya, tabel berikut memberikan batas kira-kira untuk warna-warna spektrum :

Tabel 1. Panjang Gelombang untuk spektrum warna

\begin{tabular}{cc}
\hline Warna & Panjang Gelombang (nm) \\
\hline Ungu & $380-450$ \\
Biru & $450-495$ \\
Hijau & $495-570$ \\
Kuning & $570-590$ \\
Jingga & $590-620$ \\
Merah & $620-750$ \\
\hline
\end{tabular}

\section{Metode Penelitian}

Metode yang digunakan dalam penelitian ini adalah metode eksperimen. Adapun langkah-langkah yang diambil untuk melakukan penelitian ini meliputi persiapan bahan dan alat, perakitan alat peraga sehingga seperti yang terlihat pada gambar 2, atau pada gambar 3, dan melakukan pengujian alat peraga.

\subsection{Alat dan Bahan}

Alat dan Bahan yang dibutuhkan untuk penelitian ini sebagai berikut :
a. 5 buah lampu 5 watt
b. 2 buah Fitting
c. 1 buah Steker
d. 1 meter kabel
e. Termokopel
f. Toples plastik/Sealware Komet 10 liter
g. Sumber arus listrik tegangan 220 volt

\subsection{Desain Alat Peraga Hantaran Kalor Secara Radiasi}

Alat peraga hantaran kalor secara radasi diharapkan bentuknya dapat dibuat atau dirakit dengan mudah oleh praktikan atau siswa. Adapun desain dan bentuk alat peraga tersebut dapat dilihat seperti pada gambar 2 dan gambar 3.

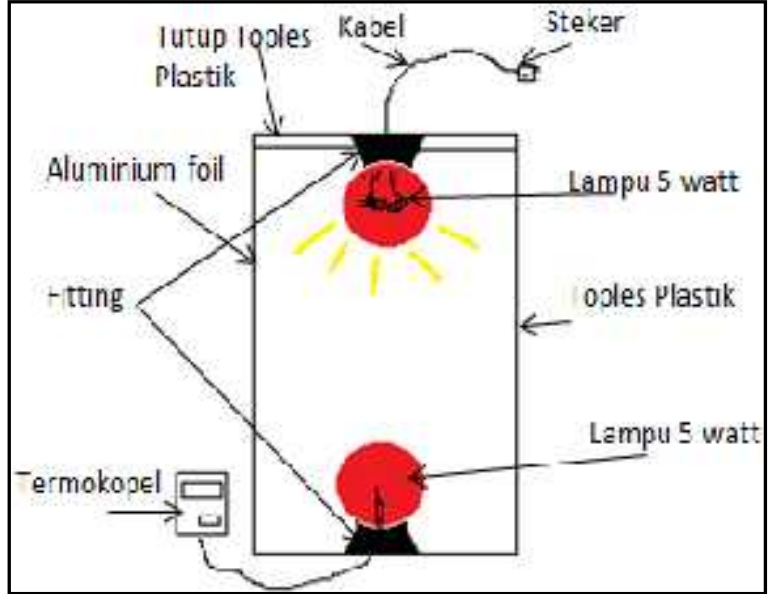

Gambar 2. konsep Alat Peraga Hantaran Kalor Secara Radiasi

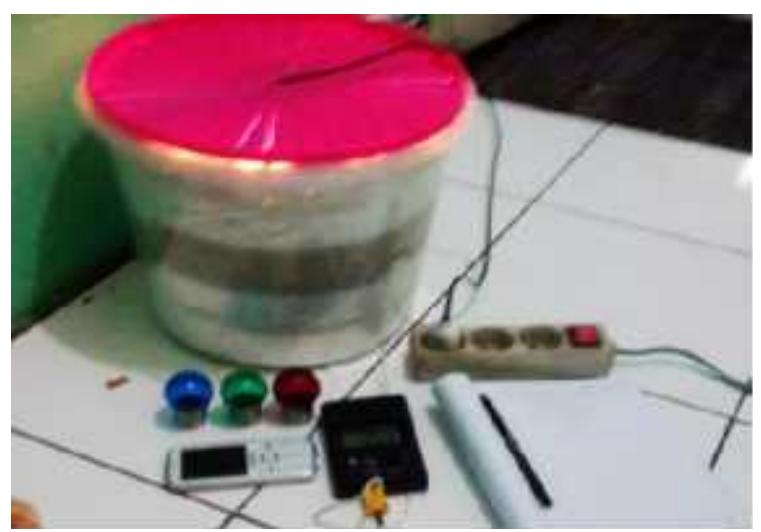

Gambar 3. Alat Peraga Hantaran Kalor Secara Radiasi

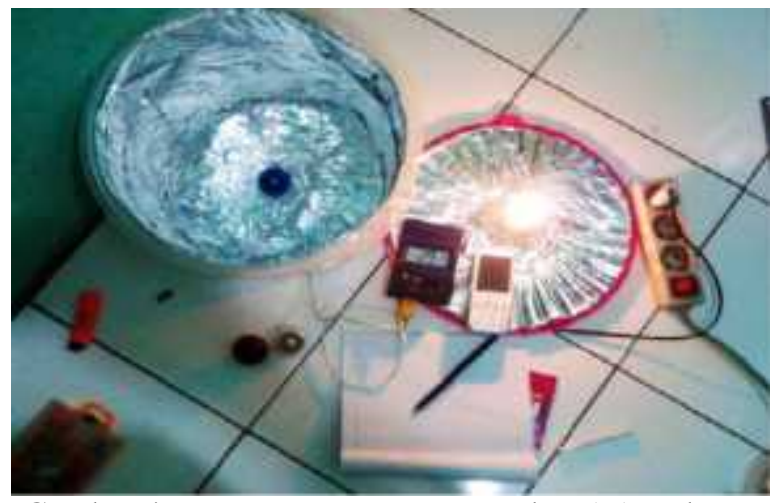

Gambar 4. Pemasangan Lampu untuk T (K) pada Alat Peraga

\subsection{Prinsip Kerja Alat}

Lampu bagian atas berwarna polos yang dipasang pada tutup toples plastik dinyalakan sehingga menjadi sumber energi kalor dalam toples yang dilapisi aluminium foil sehingga memperkuat pancaran dan mengenai lampu yang dipasang pada fitting bagian bawah sehingga lampu (Polos/Clear, Biru, Hijau, 
atau Merah) yang terkena pancaran selama waktu tertentu akan mengalami kenaikan suhu yang diukur dengan menggunakan termokopel. Kenaikkan suhu pada saat terkena pancaran sinar dalam waktu tertentu pada lampu di fitting bagian bawah berarti lampu tersebut menerima kalor dari lampu bagian atas yang berarti lampu bagian bawah dapat menyerap kalor. Setiap warna mempunyai panjang gelombang.

\subsection{Pengujian Alat Peraga}

Adapun prosedur percobaan untuk alat peraga hantaran kalor secara radiasi adalah sebagai berikut :

1. Siapkalan alat peraga hantaran kalor secara radiasi yang telah di seting seperti pada gambar 3.1.

2. Nyalakan lampu.

3. Catat suhu bola lampu berwarna yang ditunjukkan pada termokopel setiap 60 detik pada tabel pengamatan sebagai $\mathrm{T}$ (k) yang mana stiap lampu berwarna bagian bawah berulir pada lampu dibuat lubang dan bagian dalam dari lampu juga dibuang sehingga bisa digunakan untuk memasukkan kawat termokopel.

4. Catat suhu bola lampu polos/clear yang ditunjukkan pada termokopel setiap 60 detik pada tabel pengamatan sebagai $\mathrm{T}$ (k) yang mana stiap lampu berwarna bagian bawah berulir pada lampu dibuat lubang dan bagian dalam dari lampu juga dibuang sehingga bisa digunakan untuk memasukkan kawat termokopel.

5. Ulangi 1 sampai 3 untuk warna lampu berbeda

\section{Data Pengujian Alat, ANALISA dan Pembahasan}

Dari percobaan diperoleh data sebagai berikut :

1. Data hantaran kalor secara radiasi pada bola lampu berwarna merah

Panjang gelombang yang diserap bola lampu berwarna merah sebesar $\lambda=\lambda-\lambda_{0}=\mathrm{C}(1 / \mathrm{T}-1 / \mathrm{To})$.
Tabel 2. Nilai Hantaran Kalor Secara Radiasi pada Bola Lampu berwarna Merah

\begin{tabular}{|c|c|c|c|c|c|}
\hline $\begin{array}{c}\mathrm{t} \\
(\mathrm{s})\end{array}$ & $\begin{array}{c}\mathrm{T} \\
(\mathrm{K})\end{array}$ & $\begin{array}{l}\text { To } \\
\text { (K) }\end{array}$ & $\lambda(\mathrm{m})$ & $\lambda o(m)$ & $\begin{array}{c}\Delta \lambda \\
(\mathrm{nm})\end{array}$ \\
\hline 60 & 306 & 304 & $\begin{array}{c}9,48 \mathrm{E}- \\
06\end{array}$ & $\begin{array}{c}9,54 \mathrm{E}- \\
06\end{array}$ & 62,350 \\
\hline $\begin{array}{c}12 \\
0\end{array}$ & $\begin{array}{c}307, \\
2\end{array}$ & $\begin{array}{c}304, \\
8\end{array}$ & $\begin{array}{c}9,44 \mathrm{E}- \\
06\end{array}$ & $\begin{array}{l}9,51 \mathrm{E}- \\
06\end{array}$ & 74,332 \\
\hline $\begin{array}{c}18 \\
0\end{array}$ & 308 & $\begin{array}{c}305, \\
4\end{array}$ & $\begin{array}{c}9,42 \mathrm{E}- \\
06\end{array}$ & $\begin{array}{c}9,50 \mathrm{E}- \\
06\end{array}$ & 80,159 \\
\hline $\begin{array}{c}24 \\
0\end{array}$ & $\begin{array}{c}308, \\
6\end{array}$ & $\begin{array}{c}306, \\
1\end{array}$ & $\begin{array}{c}9,40 \mathrm{E}- \\
06\end{array}$ & $\begin{array}{c}9,47 \mathrm{E}- \\
06\end{array}$ & 76,750 \\
\hline $\begin{array}{c}30 \\
0\end{array}$ & $\begin{array}{c}309, \\
2\end{array}$ & $\begin{array}{c}306, \\
6\end{array}$ & $\begin{array}{c}9,38 \mathrm{E}- \\
06\end{array}$ & $\begin{array}{c}9,46 \mathrm{E}- \\
06\end{array}$ & 79,535 \\
\hline $\begin{array}{c}36 \\
0\end{array}$ & $\begin{array}{c}309, \\
6\end{array}$ & $\begin{array}{c}307, \\
1\end{array}$ & $\begin{array}{l}9,37 \mathrm{E}- \\
06\end{array}$ & $\begin{array}{l}9,44 \mathrm{E}- \\
06\end{array}$ & 76,253 \\
\hline $\begin{array}{c}42 \\
0\end{array}$ & 310 & $\begin{array}{c}307, \\
6\end{array}$ & $\begin{array}{c}9,35 \mathrm{E}- \\
06\end{array}$ & $\begin{array}{c}9,43 \mathrm{E}- \\
06\end{array}$ & 72,990 \\
\hline $\begin{array}{c}48 \\
0\end{array}$ & $\begin{array}{c}310, \\
4\end{array}$ & 308 & $\begin{array}{c}9,34 \mathrm{E}- \\
06\end{array}$ & $\begin{array}{c}9,42 \mathrm{E}- \\
06\end{array}$ & 72,801 \\
\hline $\begin{array}{c}54 \\
0\end{array}$ & $\begin{array}{c}310 \\
8\end{array}$ & $\begin{array}{c}308, \\
4\end{array}$ & $\begin{array}{c}9,33 \mathrm{E}- \\
06\end{array}$ & $\begin{array}{c}9,40 \mathrm{E}- \\
06\end{array}$ & 72,613 \\
\hline $\begin{array}{c}60 \\
0 \\
\end{array}$ & $\begin{array}{c}311, \\
1\end{array}$ & $\begin{array}{c}308, \\
7\end{array}$ & $\begin{array}{c}9,32 \mathrm{E}- \\
06\end{array}$ & $\begin{array}{c}9,39 \mathrm{E}- \\
06\end{array}$ & 72,472 \\
\hline & & & & Jumlah & $\begin{array}{c}740,25 \\
4\end{array}$ \\
\hline & & & & $\begin{array}{l}\text { Rata- } \\
\text { rata }\end{array}$ & 74,025 \\
\hline
\end{tabular}

Panjang gelombang dari percobaan $=740,254 \mathrm{~nm}$. Batas kirakira panjang gelombang warna merah sebesar $=620-750 \mathrm{~nm}$.

2. Data hantaran kalor secara radiasi pada bola lampu berwarna hijau

Panjang gelombang yang diserap bola lampu berwarna hijau sebesar $\lambda=\lambda-\lambda \mathrm{o}=\mathrm{C}(1 / \mathrm{T}-1 / \mathrm{To})$.

Tabel 3. Nilai Hantaran Kalor Secara Radiasi pada Bola Lampu berwarna Hijau

\begin{tabular}{|c|c|c|c|c|c|}
\hline $\begin{array}{l}\mathrm{t} \\
(\mathrm{s})\end{array}$ & $\begin{array}{c}\mathrm{T} \\
(\mathrm{K})\end{array}$ & $\begin{array}{l}\text { To } \\
\text { (K) }\end{array}$ & $\lambda(\mathrm{m})$ & $\lambda o(m)$ & $\begin{array}{c}\Delta \lambda \\
(\mathrm{nm})\end{array}$ \\
\hline 60 & $\begin{array}{r}305, \\
4\end{array}$ & 304 & $\begin{array}{r}9,50 \mathrm{E}- \\
06\end{array}$ & $\begin{array}{r}9,54 \mathrm{E}- \\
06\end{array}$ & 43,73 \\
\hline 12 & 306 , & 304 , & $9,47 \mathrm{E}-$ & $9,51 \mathrm{E}-$ & \\
\hline 0 & 2 & 8 & 06 & 06 & 43,502 \\
\hline 18 & & 305 , & $9,45 \mathrm{E}-$ & 9,50E- & \\
\hline 0 & 307 & 4 & 06 & 06 & 49,489 \\
\hline 24 & 307 , & 306 , & $9,43 \mathrm{E}-$ & $9,47 \mathrm{E}-$ & \\
\hline 0 & 7 & 1 & 06 & 06 & 49,264 \\
\hline 30 & 308 , & 306 , & $9,41 \mathrm{E}-$ & 9,46E- & \\
\hline 0 & 3 & 6 & 06 & 06 & 52,156 \\
\hline 36 & 308 , & 307 , & $9,39 \mathrm{E}-$ & 9,44E- & \\
\hline 0 & 8 & 1 & 06 & 06 & 51,986 \\
\hline 42 & 309 , & 307 , & $9,38 \mathrm{E}-$ & 9,43E- & \\
\hline 0 & 3 & 6 & 06 & 06 & 51,818 \\
\hline
\end{tabular}




\begin{tabular}{rrrrrr}
48 & 309, & & $9,36 \mathrm{E}-$ & $9,42 \mathrm{E}-$ & \\
0 & 7 & 308 & 06 & 06 & 51,684 \\
54 & 310, & 308, & $9,35 \mathrm{E}-$ & $9,40 \mathrm{E}-$ & \\
0 & 1 & 4 & 06 & 06 & 51,55 \\
60 & 310, & 308, & $9,34 \mathrm{E}-$ & $9,39 \mathrm{E}-$ & \\
0 & 5 & 7 & 06 & 06 & 54,459 \\
\hline & & & & Jumla & 499,63 \\
& & & & h & 8 \\
\cline { 3 - 6 } & & & & Rata- & \\
& & & & & \\
& & & & &
\end{tabular}

Panjang gelombang dari percobaan $=499638 \mathrm{~nm}$. Batas kirakira panjang gelombang warna hijau sebesar $=495-570 \mathrm{~nm}$.

3. Data hantaran kalor secara radiasi pada bola lampu berwarna biru

Panjang gelombang yang diserap bola lampu berwarna biru sebesar $\lambda=\lambda-\lambda_{0}=\mathrm{C}(1 / \mathrm{T}-1 / \mathrm{To})$.

Tabel 4. Nilai Hantaran Kalor Secara Radiasi pada Bola Lampu berwarna Biru

\begin{tabular}{|c|c|c|c|c|c|}
\hline $\begin{array}{c}\mathrm{t} \\
(\mathrm{s})\end{array}$ & $\begin{array}{c}\mathrm{T} \\
(\mathrm{K})\end{array}$ & $\begin{array}{l}\text { To } \\
\text { (K) }\end{array}$ & $\lambda(\mathrm{m})$ & $\lambda o(\mathrm{~m})$ & $\begin{array}{c}\Delta \lambda \\
(\mathrm{nm})\end{array}$ \\
\hline 60 & 305 & 304 & $\begin{array}{r}9,51 \mathrm{E}- \\
06\end{array}$ & $\begin{array}{r}9,54 \mathrm{E}- \\
06\end{array}$ & 31,277 \\
\hline 12 & 306 , & 304, & 9,47E- & $9,51 \mathrm{E}-$ & \\
\hline 0 & 3 & 8 & 06 & 06 & 46,594 \\
\hline 18 & 307 , & 305 , & $9,44 \mathrm{E}-$ & $9,50 \mathrm{E}-$ & \\
\hline 0 & 1 & 4 & 06 & 06 & 52,565 \\
\hline 24 & 307 , & 306 , & 9,42E- & $9,47 \mathrm{E}-$ & \\
\hline 0 & 8 & 1 & 06 & 06 & 52,326 \\
\hline 30 & 308 , & 306 , & $9,40 \mathrm{E}-$ & $9,46 \mathrm{E}-$ & \\
\hline 0 & 4 & 6 & 06 & 06 & 55,206 \\
\hline 36 & 308 , & 307, & 9,39E- & $9,44 \mathrm{E}-$ & \\
\hline 0 & 8 & 1 & 06 & 06 & 51,986 \\
\hline 42 & 309 , & 307, & 9,38E- & $9,43 \mathrm{E}-$ & \\
\hline 0 & 2 & 6 & 06 & 06 & 48,786 \\
\hline 48 & 309 , & & $9,37 \mathrm{E}-$ & $9,42 \mathrm{E}-$ & \\
\hline 0 & 5 & 308 & 06 & 06 & 45,633 \\
\hline 54 & 309 , & 308 & 9,36E- & $9,40 \mathrm{E}-$ & \\
\hline 0 & 8 & 4 & 06 & 06 & 42,494 \\
\hline 60 & 310 , & 308 , & 9,35E- & $9,39 \mathrm{E}-$ & \\
\hline \multirow[t]{4}{*}{0} & 1 & 7 & 06 & 06 & 42,412 \\
\hline & & & & & 469,27 \\
\hline & & & & Jumlah & 8 \\
\hline & & & & $\begin{array}{l}\text { Rata- } \\
\text { rata }\end{array}$ & 46,928 \\
\hline
\end{tabular}

Panjang gelombang dari percobaan $=469,278 \mathrm{~nm}$. Batas kirakira panjang gelombang warna biru sebesar $=450-495 \mathrm{~nm}$.

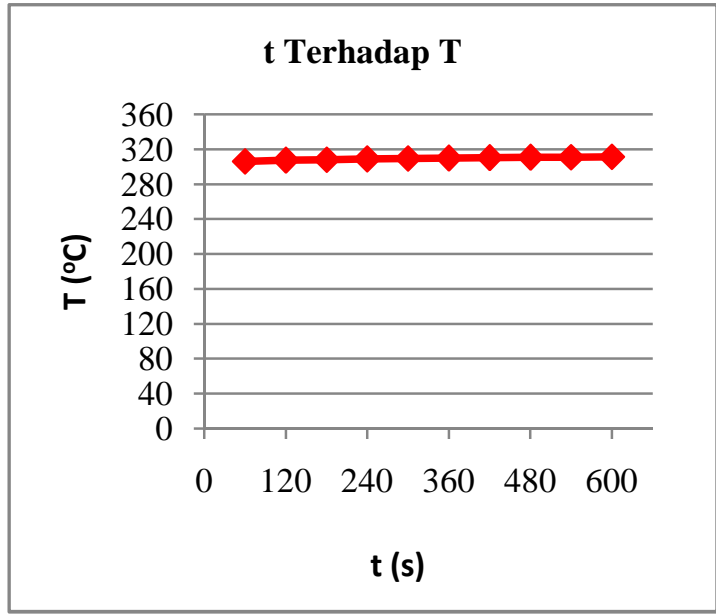

Gambar 5. Grafik Waktu terhadap Suhu Lampu Merah

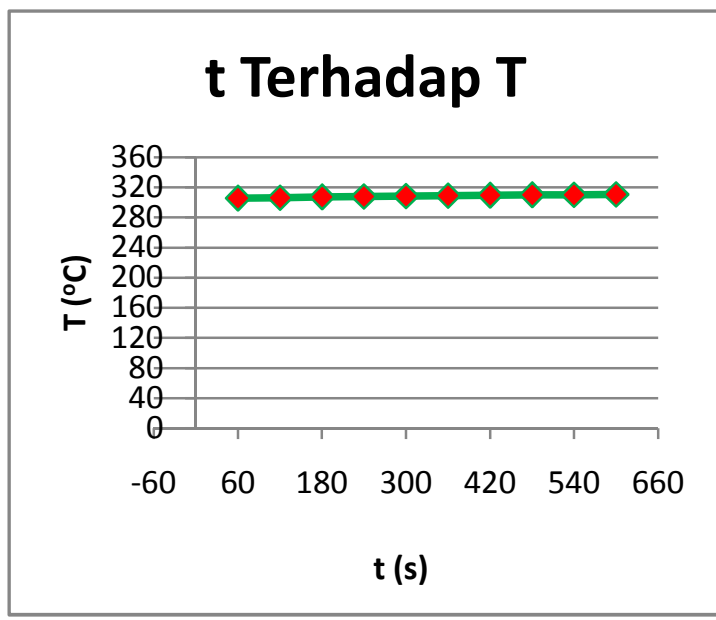

Gambar 6. Grafik Waktu terhadap Suhu Lampu Hijau

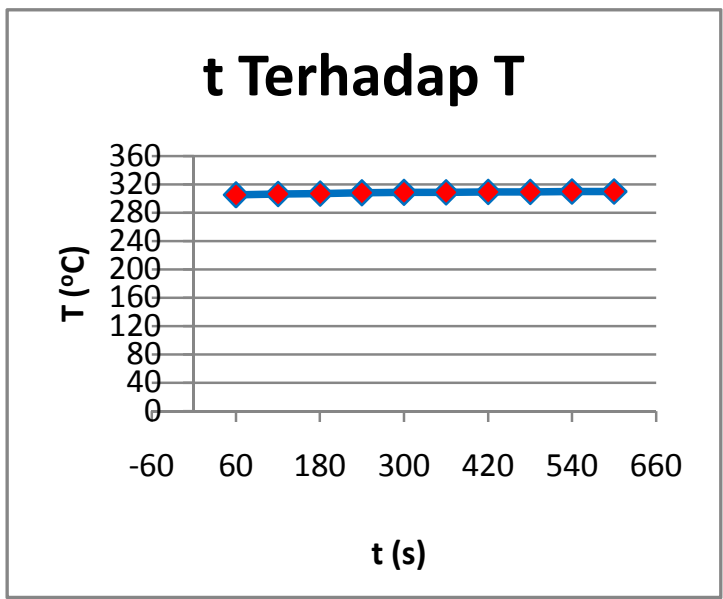

Gambar 7. Grafik Waktu terhadap Suhu Lampu Biru

Menentukan Panjang gelombang warna untuk tiap lampu berwarna secara radiasi dari percobaan yang telah dilakukan pada toples plastik berukuran 10 liter yang didalamnya dilapisi aluminium 
foil supaya panas yang dihasilkan oleh bola lampu tidak terserap oleh dinding toples dan terpancarkan keluar toples sehingga mengenai bola lampu yang diletakkan dalam alat peraga untuk baik untuk warna biru, hijau, merah, dan yang polos. Pada fenomena yang diamati dan dianalisis berupa suhu didalam lampu yang yang berwarna biru, hijau, merah, dan bola lampu polos. Terjadi perbedaan suhu pada bola lampu biru, hijau, merah, dan polos sehingga hal ini membuktikkan bahwa warna bola lampu mempengaruhi penyerapan suhu (data pada tabel 1), yang berarti setiap warna bola lampu mempunyai panjang gelombang. Panjang gelombang maksimum menurut pergeseran Wien dapat dirumuskan $\lambda$ maks $. \mathrm{T}=\mathrm{C}$. Dimana $\mathrm{C}=$ konstanta wien $=2,898 \times 10$ $3 \mathrm{mK}$. Jadi panjang gelombang yang diserap lampu biru, hijau, merah, dan polos sebesar $\lambda=\lambda-\lambda \mathrm{o}=\mathrm{C}(1 / \mathrm{T}-1 / \mathrm{To})$.

Panjang gelombang yang dihasilkan setiap bola lampu biru sebesar 469,278 $\mathrm{nm}$, bola lampu hijau sebesar 499,638 nm, dan bola lampu warna merah sebesar $740,254 \mathrm{~nm}$. Pada percobaan ini tidak semua warna yang di uji tetapi hanya 3 warna saja. Panjang gelombang yang didapatkan dari hasil percobaan pada warna biru, hijau, merah termasuk didalam interval spektrum warna yang sesuai dengan panjang gelombang masingmasing warna. Hasil percobaan menunjukkan panjang gelombang terbesar sampai terkecil pada warna bola lampu yaitu merah, hijau, dan biru.

Dari percobaan diatas dapat dilihat bahwa hasil yang diperoleh masuk dalam interval spektrum warna sehingga alat peraga ini dapat direrkomendasikan untuk praktikum karena dana yang dibutuhkan untuk membuat alat ini tidak mahal karena dapat menggunakan bekas toples pecah dirumah, dan alumunium foil yang digunakan dapat menggunakan sisa almunium foil untuk makanan yang dimiliki.

\section{Kesimpulan}

Panjang gelombang yang didapatkan dari percobaan pada warna biru, hijau, dan merah termasuk dalam interval spektrum warna yang sesuai dengan panjang gelombang masing-masing warna. Panjang gelombang terbesar sampai terkecil pada warna bola lampu merah, hijau, dan biru yakni secara berurutan dengan panjang gelombang 740,254 nm, 499,638 nm, dan $469,278 \mathrm{~nm}$.

\section{Saran}

Sebaiknya pada saat melakukan penelitian jaga keselamatan untuk diri praktikan, alat, dan bahan. Setelah dilakukan percobaan ini maka penelitian ini dapat digunakan sebagai alat peraga untuk menentukan panjang gelombang oleh rekan-rekan guru di sekolah yang mengampu mata pelajaran Fisika atau digunakan untuk praktikum siswa.

\section{Daftar pustaka}

[1] On ,Tjia May Dr, 2000, Pembelajaran Fisika Di Indonesia Membunuh Kreativitas Murid, Harian Kompas, Edisi Senin 1 mei 2000.

[2] Rosyid, M.F, Dr. rer. Nat., 2008, " $D i$ Indonesia, Ilmu Fisika Secara Sistematis Terpenjara Di Sekolahan dan Bimbingan Test", disampaikan dalam Seminar Nasional Fisika dan Pendidikan Fisika Di Universitas Ahmad Dahlan.

[3] Undang-Undang Republik Indonesia Nomor 15 Tahun 2005 Tentang Guru dan Dosen. 30 Desember 2005. Jakarta : Lembaran Negara Republik Indonesia Tahun 2005 Nomor 157.

[4] Krane, Kenneth S. (2014), Fisika Modern/Kenneth S. Krane; Penerjemah, Hans J. Wospakrik, Pendamping, Sofia Niksolihin, Jakarta : Universitas Indonesia (UI-Press).

[5] http://edupaint.com/warna/roda-warna/ 484-read-110617-spektrum-optik.html 